\title{
After innovation: protecting intellectual property during production - Canica Design Inc
}

by Prescott C. Ensign (Telfer School of Management, University of Ottawa, Ontario, Canada, e-mail: ensign@telfer.uottawa.ca) and Andrew Lanney (Canadian International Development Agency, Gatineau, Québec, Canada)

The Case Study section of the International Journal of Entrepreneurship and Innovation serves two purposes. First, the case studies presented are concerned with problematical issues that are pertinent to students of entrepreneurship. Thus they constitute appropriate teaching and learning vehicles on a variety of postgraduate and undergraduate programmes. Each case study is accompanied by a set of guidelines for the use of tutors. Second, it is envisaged that those engaged in entrepreneurial activities will find the cases both interesting and useful.

This case study examines the challenges of a small product design company to bring innovative surgical instruments and wound closure devices to domestic and international medical markets quickly and efficiently, while still protecting intellectual property.

This case looks over the shoulders of Alden Rattew, Executive Vice-President of Canica Design Inc, as he manages unique pressures and expectations. Balancing a hectic promotional trade show schedule, leading an innovative corporate culture and an ultra-lean workforce, Alden is tasked with developing and executing a manufacturing strategy that safeguards intellectual property and will satisfy the company's board of directors at the next month's meeting. Guiding Canica's most promising new product to market while preserving its intellectual property occupies Alden's full attention.

\section{Canica's roots}

In 1998, Leonard Lee was at the helm of Lee Valley Tools, a thriving enterprise that offered quality woodworking and gardening tools through 13 locations across Canada and via mail order worldwide. Mr Lee had earlier spun off Veritas for the design and manufacture of those tools, and also Algrove Publishing, which specialized in gardening and woodworking titles. But his latest venture, which coincided with the passing of the Lee Valley corporate reins to his son, was Canica - a business that had found him.

A physician by the name of Michael Bell had been using a number of off-theshelf woodworking knives in the operating theatre for surgical procedures. Dr Bell contacted Lee Valley Tools to suggest modifications to a woodcarving tool he had bought. The instrument was corroding, despite an unconditional guarantee that it would not rust. Dr Bell insisted that he did want a replacement, but that he had some suggestions for its improvement. Unknown to Mr Lee, the doctor had been using the carving knife in surgery and the corrosion was a result of repeated autoclaving. ${ }^{1}$

Recognizing a new challenge, Mr Lee assembled a team from his tool design programme to meet Dr Bell and discuss his ideas further. Dr Bell insisted that the improvised Lee Valley instruments were better than existing industry products. After a frank discussion, Dr Bell made a strong case for the team to design a new surgical scalpel: 'there just weren't any good ones on the market'.

'While many complicated new devices have been created for medicine by modern technology, simpler instruments such as sutures, scalpels and clamps haven't changed much in the last 100 years.' Continuing, Mr Lee summarized, 'This is the first major change in the scalpel since 1915'. Mike O'Malley, Canica's R\&D Director, noted that surgical instrument makers had concentrated on the high-ticket items, leaving the basic tools neglected. Mr Lee interjected, 'We want to restore the longsince forgotten relationship between the makers of surgical instruments and the doctors who use them'.

Lee Valley's Industrial Designer, Tim Maxwell, completed the new scalpel design and, shortly thereafter a new company, Canica Design, was born.

\section{Fast-forward to today}

By 2007, Canica was on its secondgeneration scalpel - the company's flagship product, which shouldered over $90 \%$ of revenues for a young enterprise employing 15 people full-time. A series of innovative products had been developed and now totalled more than 40 items in several distinct product lines.

Canica designed and produced medical/surgical tools and supplies for the healthcare industry, but was foremost a company of innovation.

Its wound closure solutions included a variety of dynamic devices to speed up healing and minimize scarring. Tissue could be stretched with these various devices - with dramatic effects. The elastomers were proving to be miraculous - on American soldiers with serious injuries, the results were stunning, eliminating the need for skin grafts. Reaping the rewards for past 
investments, Canica was projecting to have its first profitable year since incorporation, and revenues were expected to reach $\$ 5$ million in the next three years (Business Edge, 29 September 2006).

Building upon this success and seeking to capitalize on Canica's growing identity as a quality innovator for the international medical industry, the design team had produced yet another innovative product - SutureSafe ${ }^{\mathrm{TM}}$.

\section{The product}

Designed by biomedical engineer Matthew Archibald with input from Dr Bell, SutureSafe ${ }^{\mathrm{TM}}$ was a remarkable 'Band-aid' (which was actually a registered trademark of Johnson \& Johnson) to "isolate surgical incisions, allowing patients to move without pain'. Dr Bell's pride in these magical adhesive bandages was evident: "with the growing emphasis on day surgeries, patient discharge remains contingent on comfort and mobility. SutureSafe ${ }^{\text {TM }}$ dramatically improves both.'

SutureSafe ${ }^{\mathrm{TM}}$ looked deceptively simple. Applied as a bridge across the incision line, the stretchy adhesive fabric bonded to undamaged skin, dynamically drawing the wound margins together. A non-elastic layer was used to set the application tension, allowing the patient to move without sharp pain and preventing the wound from opening under sudden strain (quick movement, coughing, sneezing, etc).

The SutureSafe ${ }^{\mathrm{TM}}$ product launch at the Association of Perioperative Registered Nurses 53rd Congress resulted in wide praise and over $80 \%$ of attendees wanting a sample strip. Canica was very optimistic about the product's potential. Given this favourable acceptance, combined with the wide applicability of SutureSafe ${ }^{\mathrm{TM}}$ for any type of wound position, the product was expected to pull market share from sales for metal skin staples and staplers, the long-standing industry norm that had displaced stitches.

\section{Stakeholder perspectives}

Regional, national and international media buzz reinforced the value of the work Canica was doing; however, none of this would matter if there were a significant delay in making the product market-ready. Capitalizing and building on momentum was essential; a viable production strategy was paramount. Alden estimated that the product should begin sales distribution in six months. The 'time to market' question needed resolution with consideration of all sides. From the shareholders to the various management teams, Alden sought to summarize the perspectives of each of the key stakeholder groups.

With three weeks to go, Alden reasoned that there was insufficient time for extensive consultation outside the company. He knew the first step would be to open dialogue and identify the specific complexities of manufacturing the product. Internal consultation was always fruitful. Canica's 15 employees were avid information sharers, acutely aware of the situation, often before they were asked. In view of this, Alden was certain he could confirm the validity of their input with academic and industry resources.

Responsible for researching the stakeholder perspectives, Cindy LaRocque, Customer Service Coordinator and Assistant to the Executive VP, used the company's shared network drive and shared e-mail drive to glean and assemble the positions of the various stakeholder groups.

Investors. Sensing the company was on track to achieve another series of corporate milestones with SutureSafe ${ }^{\mathrm{TM}}$, the topic of 'time to market' was inherently hot. Most conversations among the board were speculative; bringing SutureSafe ${ }^{\text {TM }}$ to the USA and EU would necessitate revising the already beefy growth forecasts for the next three fiscal years. From their perspective, the proverbial 'stick in the spokes' resided with the manufacturing issue, but shareholder chatter certainly generated a lot of excitement.

The combination of known product potential, the non-existence of similar products, and an overall impatience with the time required to gain customer acceptance in the medical industry had begun to frustrate Canica's eager investors. This haste was further compounded by the potential loss of competitive advantage if a knock-off product came to market before Canica had established sales distribution for each market. If this happened, imitators would quickly erode the competitive advantage SutureSafe ${ }^{\text {TM }}$ had yet to capitalize on.

There was also the worry that Canica would forever be a 'one-trick pony', referring to the fact that most of the revenue came from scalpel sales. The thought of another year with only one significant revenue stream was repeatedly cited as a concern at board meetings.

Two months earlier, a shareholder representing venture capital interests had circulated a document to the board outlining some of their research on the manufacturing issue. It was believed that the company was not adequately positioned to absorb product-manufacturing responsibilities and therefore should seek outsourcing contracts for SutureSafe ${ }^{\mathrm{TM}}$. This was another way of suggesting that expanding operations, plus hiring and training new staff, would not be easily financed.

Given the investor's position on the matter, Alden knew that submitting a proposal for more funding to acquire the necessary infrastructure for an in-house operation would create some frustration (not to mention the months of planning that would be required). Building a whole new infrastructure for a single product might weaken the company's financial position. He questioned whether this would be an acceptable level of risk for the shareholders. But in the long run, would outsourcing be most costeffective?

Operations management. Canica's operations were the essence of Alden's management responsibilities. From this stance, it made sense to try to recoup the research and development costs as soon as possible. After all, Canica was primarily research and developmentdriven, and this was reflected in the staff education, training and other core competencies.

Perhaps a mixed approach would strengthen the burgeoning enterprise? Outsource now and when sales stabilized, shift some of the production in-house if the unit production costs were comparable. Alden knew one thing was certain: if the demand for SutureSafe ${ }^{\mathrm{TM}}$ exceeded the numbers for the scalpel, the management burden would probably strain Canica's current personnel resources.

At this juncture, the design and 
operations team had yet to ascertain the actual unit cost of manufacturing the SutureSafe ${ }^{\mathrm{TM}}$ samples, so there were few quantitative data to go on to support an in-house production alternative.

Product design team. Mike O'Malley, Vice-President of R\&D, maintained that every possible safeguard must be taken to ensure the security of Canica's intellectual property (IP). SutureSafe ${ }^{\mathrm{TM}}$ required significant investments of people, technology, money, and over 14 months to develop it. Mr O'Malley did not like the idea of outsourcing, especially to a foreign company.

Alden recalled the lengthy conversation they had shared only three months earlier about the dreaded efficiency of reverse engineering. Copycats entering the market would derail Canica's IP advantage. 'Each country has its own IP laws and regulations and $\mathrm{R} \& \mathrm{D}$ are so costly, there is always someone looking for a shortcut. China, as an example, has an unbelievably poor IP protection record. Labour costs may be cheaper, but at what cost?' 'The ramifications of a knock-off hitting the market before we do... consider the implications if the knock-off hits a major distributor before us,' affirmed O'Malley.

Having witnessed the incredible process to bring an idea to prototype and the amount of investment required, Alden was in agreement that protecting the IP was certainly a base requirement for the decision.

Materials and quality management. Following the decision to outsource the scalpel's manufacturing, Steve Kerr, Materials and Quality Coordinator, and Kathleen Whalen, Materials Assistant, had authored an internal briefing on the importance of production oversight and feedback to improve product quality. From the briefing, the following excerpts were highlighted by Ms LaRocque, Alden's assistant:

'The value of our products is inherently tied to the quality of our manufacturing process. Oversight of the production process is essential to ensure this value.'

'The norm for production is that it is a learning process. Initial production almost always has a higher defectives rate, but if the initial training and equipment is adequate, the producers realize their errors and provide feedback on the product design, quality will improve and defect rates will decrease. Manufacturing is as much a part of the iterative process of product design as the initial design itself. This feedback affords incredible opportunities for product improvement and quality assurance.'

'Not all manufacturers can accommodate low-scale production quotas. The response time may be long because small projects have low priority, which could hinder the ability to establish prompt product delivery timelines.'

'We strongly recommend manufacturers be responsible for all aspects of production, complete from raw materials sourcing to final product packaging and labelling so as to reduce further manipulation/handling costs.'

Consumer. Representing the consumer perspective was Canica's long-time technical adviser, physician Michael Bell. There was no information on the shared network drive relating to the consumer angle, so Alden and Canica's President, Mr Lee, held a telephone conference with Dr Bell to obtain his input.

Dr Bell urged them to consider that whatever the solution was for manufacturing, it must ensure a strong product value - quality and a good price for the people using the product - from the clinician to the patient.

Leonard Lee strongly supported this point and added that the manufacturer should ideally be located close to or within the markets for the product, so as to minimize additional costs of shipping, taxes and trade tariffs.

Reflecting on the incredible success of Lee Valley Tools, Alden could reasonably expect support from Canica's President for this option. Mr Lee had made a legacy of keeping all elements of operations Canadian, and this 'Made in Canada' mentality had served to strengthen Lee Valley for the long run surely such an approach could also work for Canica in its industry.

\section{Outsourcing}

Continuing to scan through the dossier that Cindy LaRocque had consolidated, Alden focused on notes from a 2002 consultation on the subject of global outsourcing:

'Global outsourcing presents a number of pitfalls, but in a more virulent form. Just as our documentation can be cryptic to foreign users, agreements and contracts with overseas partners can be misinterpreted as well. The danger of sacrificing core competences is also exacerbated. Intellectual property laws differ from country to country. In general, it is important to know the laws governing your prospective outsourcing partner.'

'On the global trend to outsource to East Asian countries like China, South Korea, intellectual property protection is an issue. What good is a patent if some companies don't respect the legal right of ownership? Why would we simply hand over our schematics and product design plans to a manufacturer in a country that will simply produce knock-offs on the side at a discounted rate and erode our position in the marketplace?'

\section{Target markets}

The big markets were the USA, EU and Canada. The number of hospitals was the primary indicator of market size: as of 2005, Europe ranked highest with 13,581; the USA followed with 7,569; and Canada had 2,164 hospitals. These figures were at best rough estimates of potential facilities that might use SutureSafe ${ }^{\mathrm{TM}}$. The number of private clinics was more difficult to estimate, but they were substantial and growing. Projected sales. Ideally, a five-year sales projection would guide the process of assessing market strength and profitability. This assessment could be expanded to forecast at the regional, city, and perhaps even purchasing conglomerate level.

According to the Minneapolis St. Paul Business Journal, more than eight million metal skin staplers had been sold in the US market in 2003, and the worldwide market was twice that figure. But 
these numbers did not give any insight into the potential sales of the new suture.

Market potential was quite elusive to obtain for new product designs. Since SutureSafe ${ }^{\mathrm{TM}}$ was designed for any/all types of wounds, it was virtually impossible to estimate with any degree of certainty the expected number of units to be sold. Moreover, since there were no similar products on the market, a comparative study against the demand for stapler/staple sales would not help even if the data were available.

Another means to forecast demand could be attempted via identifying the types of procedures the product would be used for and aggregating the number of procedures. This assessment method also seemed flawed: there were far too many variations to account for (clinician's judgment, the number of strips to use, size of incision, etc). Sales forecasts would be raw assessments at best and unsupportive to projecting production volumes. In summary, sales forecasting could be wholly inaccurate.

\section{Maintaining momentum}

Alden Rattew, Executive Vice-President of Canica Design Inc, assessed the realities facing this fledgling venture - if outsourcing was in order, what next? The how, where and who were yet to be determined.

Things were going well: Canica was establishing a strong distribution network in Canada, the USA and Europe for its scalpels. But the big agenda item remained Canica's next product of promise, SutureSafe ${ }^{\mathrm{TM}}$. After a short status report from Alden on the positive feedback received at a recent trade show in Chicago, a member of the board inquired about the manufacturing strategy for the product - and therein lay the true, immediate pressure. Having completed clinical trials and gained regulatory approval in Canada, the USA and EU, attention now turned to discussing market readiness.

If the process of commercializing the scalpel had taught Alden anything, it was to anticipate the 'time to market' question from investors and the board. Unfortunately, the two products were completely different in terms of design. The manufacturing strategy for the scalpel could not be replicated for SutureSafe ${ }^{\mathrm{TM}}$; nor would it provide much of a template. For the two scalpels, Canica built only the handles and, unlike the blades, handles did not have to be produced in a sterile environment - something that SutureSafe ${ }^{\mathrm{TM}}$ would definitely require.

A new strategy was needed. Leaning back in his chair staring intently at Europe and North America on the world map mounted on his office wall, Alden wondered how he could put the complete picture together. His eyes drifted over to China, Russia, and then scanned India and South-east Asia. Alden murmured, 'It looks like we will need to outsource, but what about IP? What kind of growing pains should we prepare for? How can we ensure a good value to proposition?'

As one question led to another, a parallel thread of ideas emerged and overcame him. By delivering this product to market, he would achieve one of the personal milestones he had set when he began five years ago - to strengthen the venture through a series of unique, diversified revenue streams. From speculation to motivation, the bigger picture was clearly in view: Canica must diversify one product at a time.

Unfortunately, time was the pressure. The board had requested an assessment and recommendations to be presented at their next meeting, just three weeks hence. 


\section{TEACHING NOTE ${ }^{2}$}

This case is intended for an undergraduate or graduate course in entrepreneurship. In particular, the case study highlights issues related to growing an enterprise, managing innovation (protecting technology, in particular), building value, and diversification. The case follows protagonist Alden Rattew as he tries to take Canica Design past its initial product and to avoid being a 'onehit wonder'. He is charged with evaluating the manufacturing decision. In-house or outsource? Onshore or offshore? Protecting intellectual property and expeditiously getting the product to market are prime concerns.

\section{Key issues}

The case study focuses on the pressures a start-up must withstand to survive and thrive in a highly competitive marketplace. It illustrates the critical role a senior manager must play in leading an enterprise, balancing investor and management interests, while remaining true to corporate objectives and core competencies. Finally, it illustrates a notso-uncommon threat start-ups see when surrounded by better resourced incumbents and a host of unknown imitators ready to copy their design and beat them to market.

The case calls for action. Alden Rattew must process information in several realms and, through analysis, resolve the situation in front of him and present a course for Canica to his board of directors.

Canica is innovation-driven; protecting its ideas on their way to market is vital. Getting those products to market swiftly is equally important.

Canica's management is confident in the value of its products, but also realistic and under no illusion that competitors will not arise and be able to mount a significant attack.

\section{Estimating market size}

Before coming to a conclusion with regard to manufacturing, it is worthwhile to consider how much capacity is needed.

While Canica may wish to start out with smaller batches or small production runs for SutureSafe ${ }^{\mathrm{TM}}$, there would be a lot of difficulties if Canica were fortunate enough to find itself in a situation where it needed to ramp up volume rapidly in response to market demand.

Canica must seek balance; overcapacity must also be guarded against. Canica cannot afford to have too much unsold inventory in its distribution channels.

The response from nurses at trade shows was positive. Canica has actively sought affirmation from other constituents - a visit to Canica's Website (www.canica.com) reveals its road show travel schedule. Informing these users should 'pull' the product to market.

International media attention for SutureSafe's ${ }^{\mathrm{TM}}$ miraculous effects in cases of severe trauma (combat wounds) should create a 'buzz' for non-military applications.

Students must assess the number of hospitals and clinics that are likely to replace staples.

\section{Production decision}

Selecting a manufacturer for the USA, Canada or Europe rests upon the candidate manufacturing facility's qualifications.

Each jurisdiction has minimum requirements for the manufacture of medical products. Depending on how the regulatory authorities classify the product being manufactured, the base criteria could consist of an ISO-registered and approved facility. Canica might expect a 4-12-month investment to complete the process and gain approval under the authority of the regulatory bodies (eg Health Canada, European Medicines Agency or US Food and Drug Administration).

Product packaging, storage and shipping could reasonably be expected from the manufacturer. In choosing a manufacturer, Canica might consider the costs/benefits of selecting one whose location can avoid costly tariffs and other expenses. In addition to fiscal costs, the physical distance to the market and the shipping method must be contemplated.

The final product, packaging and all, would not weigh too much or take up much space (high dollar value per weight and volume). Even if shipped from Asia, costs and time should not prove too much of a hurdle.

There were two certainties if Canica opted to expand existing operations and manufacture SutureSafe ${ }^{\mathrm{TM}}$ in-house: it would require time and money. On the upside, the IP would be as safe as it could possibly be - product design documentation would neither be duplicated nor entrusted to an external party.

Furthermore, expanding operations to accommodate a dedicated manufacturing capacity could transform the company and better position it to support future product designs and innovations. Inhouse manufacturing would also guarantee that all aspects of product development would be executed and controlled internally, ensuring complete production oversight and quality controls. Also, hiring a new team or re-training some staff would strengthen overall knowledge of the product and allow for feedback to improve the product over time, thereby improving product quality and value to the consumer.

Another element in the equation is the company's location - Almonte, Ontario. The availability of a skilled workforce to match the company's growth over time will probably be a point of contention for the board/investors. On the upside, quaint Almonte, with a population of 5,000 , is $40 \mathrm{~km}$ from Ottawa, Ontario - the national capital. Ottawa is home to a booming technology and life sciences sector and a population of one million people.

Given that Canica did not frequently use production skills, a case could be made to contract out for them. Even if Canica trained people in speciality skills, it might not be able to maintain them because of sporadic use.

Responsive production is necessary. However, for most new products sales forecasting is a challenge, if not completely speculative. Since the need for responsive production is essential, the next logical question relates to the cost for this level of service. Alden should anticipate that production 'switching costs' would come at a premium. What options would a prospective manufacturer offer to set production volumes (minimums)?

Controlling and mitigating such variable costs is fundamental to maintaining stable profit margins per unit. 
This situation would also increase contextual elements of reporting and decrease the validity of comparing financial reports from quarter to quarter, year to year; simply put, this adds a burdensome tracking activity for management.

The board would also have their questions about this relationship, as profit per unit is frequently on their minds. Chief among the desires of the investors/ board would be immediate outsourcing, thereby ensuring a rapid time to market, but would variable profit margins impact on their position? Outsourcing production could allow Canica to be sufficiently responsive to meet demand without heavy investment in developing internal production capacity.

Other questions arise from the research that point to tendering for manufacture: should Canica outsource locally (eg Ottawa and surrounding area); outsource domestically (elsewhere in Canada or perhaps within North America); or outsource to a more distant location? The idea of moderate oversight during production, the scale of risk related to IP, and accessibility to the target markets all need to be addressed.

\section{Financing}

Canica does not have endless capital to fuel growth, but there is some indication that it has or could access a pretty good supply of cash (private investors,
Leonard Lee himself, and perhaps Lee Valley Tools). Most firms must pay for future prospects (advertising, product development, etc) with past successes. Canica was following this tradition by using revenues from its two scalpel products. Canica has the stamina (financial and other resources) to survive a protracted dry spell, but there is no reason to embrace a 'dry spell' if it can be avoided.

\section{Notes}

${ }^{1}$ An autoclave is a device to expose items to steam at a high pressure in order to decontaminate the materials or render them sterile.

${ }^{2} \mathrm{~A}$ more complete teaching note is available to instructors using or contemplating using this case. Please contact Prescott C. Ensign at ensign@telfer. uottawa.ca

\section{Suggested reading}

Crane, F. G., and Sohl, J. E. (2004), 'Imperatives for venture success: entrepreneurs speak', International Journal of Entrepreneurship and Innovation, Vol 5, No 2, pp 99-106.

Dabhikar, M., and Bengtsson, L. (2008), 'Invest or divest? On the relative improvement potential in outsourcing manufacturing', Production Planning and Control, Vol 19, No 3, pp 212-228.

Ensign, P. C. (2007), 'Managing global offshoring strategies - book review', Journal of International Business Studies, Vol 38, No 1, pp 207-210.
Golan, Y. (2008), 'Insights on outsourcing', Investors' Digest, Vol 24, No 2, pp 2829.

Hoecht, A., and Trott, P. (2006), 'Innovation risks of strategic outsourcing', Technovation, Vol 26, No 5/6, pp 672681.

Kingston, W. (2001), 'Protecting the inventions of smaller high-tech firms', International Journal of Entrepreneurship and Innovation, Vol 2, No 1, pp 5-12.

Kotabe, J., Mol, M. J., and Ketkar, S. (2008), 'An evolutionary stage model of outsourcing and competence destruction', Management International Review, Vol 48, No 1, pp 65-93.

Kuratko, D. F., Hornsby, J. S., and Goldsby, M. G. (2004), 'Sustaining corporate entrepreneurship: modelling perceived implementation and outcome comparisons at organizational and individual levels', International Journal of Entrepreneurship and Innovation, Vol 5, No 2, pp 77-89.

Noel, T.W., and Latham, G. P. (2006), 'The importance of learning goals versus outcome goals for entrepreneurs', International Journal of Entrepreneurship and Innovation, Vol 7, No 4, pp 213-220.

Saemundsson, R. J. (2003), 'The interaction between growth intentions, access to resources and growth in new technology-based firms', International Journal of Entrepreneurship and Innovation, Vol 4, No 2, pp 85-95.

Tidd, J., and Barnes, S. (2000), 'Spin-in or spin-out? Corporate venturing in life sciences', International Journal of Entrepreneurship and Innovation, Vol 1, No 2, pp 109-116.

Timmons, J. A., and Spinelli, S. (2007), New Venture Creation, McGraw-Hill, Boston, MA. 